\title{
URBAN TRANSPORT VIBRATIONS AND CULTURAL HERITAGE SITES IN ROME: THE CASES OF THE TEMPLE OF MINERVA MEDICA AND OF THE CATACOMB OF PRISCILLA
}

\author{
IVAN ROSELLI ${ }^{1}$, VINCENZO FIORITI ${ }^{1}$, IRENE BELLAGAMBA ${ }^{1}$, \\ MARIALUISA MONGELLI ${ }^{1}$, ANGELO TATİ ${ }^{1}$, MARIAROSARIA BARBERA $^{2}$, \\ MARINA MAGNANI CIANETTI ${ }^{2}$ \& GERARDO DE CANIO ${ }^{1}$ \\ ${ }^{1}$ ENEA Italian National Agency for New Technologies, Energy and Sustainable Economic Development, Italy \\ ${ }^{2}$ Soprintendenza speciale per i Beni Archeologici di Roma, Italy
}

\begin{abstract}
The coexistence of modern transport systems with the presence of cultural heritage sites in urban environments is a very crucial issue in sustainable city planning. In particular, in the historic centre of cities with plenty of scattered archaeological sites, such as Rome, urban traffic vibrations must be monitored to assure the conservation of ancient monuments. In fact, cultural heritage sites may suffer from traffic vibration impact in terms of aesthetical damages even in cases in which the structural health is not compromised. In such context, the present paper focuses on the impact of traffic vibrations induced on two monuments studied within the CO.B.RA. project (aiming at developing advanced technologies and methods for the conservation of cultural heritage). The so-called Temple of Minerva Medica and the Catacomb of Priscilla are exposed to different types of traffic vibration sources and are characterized by different structural conditions. Besides the ambient vibration monitoring, several non-destructive tests (NDTs) and noncontact investigations were conducted at the two sites in order to study the state of damage and the structural conditions of the two monuments. In particular, the ambient vibration monitoring gave remarkably different outcomes in these two cases and provided objective data for interesting observations on the sustainability of tramways, railways and road traffic near such diverse archaeological assets.
\end{abstract}

Keywords: urban transport vibrations, archaeological sites, structural health, non-destructive investigations, $3 D$ reconstruction.

\section{INTRODUCTION}

Urban transport sustainability is one of the most crucial issues for contemporary cities planners. It implies the solution of typical problems related to people and freight mobility in urban areas, such as reasonable travel time and economic feasibility of transport infrastructures. As a general consideration, any relationship between the city parts and their connections with urban anthropic activities should be taken into account. Thus, the dynamics of its networks and infrastructures, such as the urban transport systems, are fundamental to assess the sustainability of modern cities.

In the latest decades, also growing environmental challenges became more and more decisive for the definition of urban sustainability. In fact, recent studies focused on the impact of transport systems in social and economic terms [1], as well as on the human health (especially in terms of safety, pollutants emissions and traffic noise) and on the overall environment (especially in terms of energy consumption and climate changes) [2]. As a consequence, urban transport sustainability indicators and indexes were recently proposed with particular emphasis on climate friendly travel choices by urban travellers and commuters [3].

On the other hand, other authors [4], propose that a more generalized definition of sustainable transport should be considered, in accordance with the Brundtland Commission 
[5], stating that sustainable means meeting the needs of the present without sacrificing the ability of future generations to do the same in terms of economic, social and human development, including environmental and ecological health. From this point of view, the historic centres of ancient cities, like Rome, often present archaeological assets and cultural heritage sites, whose maintenance and preservation for the next generations are of primary importance. In many cases, archaeological monuments suffer from aesthetical and structural problems that can be worsened in urban environment for the presence of a variety of vibration sources, such as traffic vehicles, that can induce dangerous fatigue and resonance phenomena to the structures [6]. In such contexts, the sustainability of transport systems should be evaluated also in terms of potential impact of their long-term traffic vibrations to the structural and aesthetical health of the monuments.

In the present paper two cases of archaeological sites located in Rome are illustrated. They were studied within the CO.B.RA. project, which aims at developing advanced technologies and methods for the conservation of cultural heritage [7]. The first case is represented by the so-called Temple of Minerva Medica, while the second one is the Catacomb of Priscilla. They are both exposed to traffic vibration, but of different source types, and are characterized by different structural conditions. The vibration sources were classified as tram, train and road traffic in order to assess the different impact of different transport systems.

\section{VIBRATION ASSESSMENT IN ARCHEOLOGICAL STRUCTURES}

Vibration data were collected and analysed according to the recommendations indicated by international and national regulations. In particular, the potential impact of vibrations on the structural stability of urban constructions encouraged the development of specific standards and regulations in several countries. They are substantially coherent in their indications about the methods for the measurement procedures (type and location of the instrumentation, data processing and analysis, etc.), which mostly comply with internationally widely accepted ISO 4866 standard.

The key parameter considered for assessing the intensity of vibration is the Peak Particle Velocity (PPV), that is the maximum value of vector velocity recorded in triaxial acquisitions. Alternatively, other standards consider the Peak Component Particle Velocity (PCPV), which is simply the maximum value of velocity recorded in each triaxial direction. Vibration intensity limits are generally differentiated by essentially two possible typology of duration, which can be summarised in short-term (occasional or transient events) and longterm vibrations (permanent or continuous events that might cause fatigue and resonance in the structure). As long-term vibrations are considered potentially more dangerous, standards designate stricter limits independently on the vibration frequencies. More specifically, the limits for historic buildings subjected to long-term vibrations are comprised between 1.5 and $3.0 \mathrm{~mm} / \mathrm{s}$ in terms of PPV or PCPV in most international standards and recommendations. The Italian standard UNI 9916 provides no specific limit, but cites several foreign standards, some of which do state the following specific limits for historic buildings: German DIN 4150 indicates PCPV should be limited to $2.5 \mathrm{~mm} / \mathrm{s}$ [8], while Swiss SN 640312 a) prescribes PPV $<1.5 \mathrm{~mm} / \mathrm{s}$ [9]. Vibration data in the two cases illustrated in the following were acquired using the same instrumentation, comprised of digital recorders equipped with triaxial velocimeters provided with a GPS antenna for time synchronization.

\section{CASE 1: THE TEMPLE OF MINERVA MEDICA}

The first case study that we describe is related to the traffic vibrations induce to an ancient ruined building located in the historic centre of Rome. It is erroneously called Temple of Minerva Medica since the $16^{\text {th }}$ century, because it was then thought to be a temple dedicated 
to the ancient deity of Minerva Medica ("Minerva the Doctor") and is still today widely known through such appellation, even if archaeologists presume it should have been an ancient nymphaeum built in the early $4^{\text {th }}$ century A.D of Imperial Rome, probably part of the Horti Liciniani [10].

During the centuries, the structural damages concentrated on the south side, which resulted in eventual almost complete collapse of this portion of the building by the $17^{\text {th }}$ century (Fig. 1(a)). This could be due to the presence of weaker foundations on the south side, as recent investigations highlighted [10]. After major restoration interventions were conducted in 1846 (for the reconstruction of first floor arcade) and more recently in 2012-2013 (reconstruction of upper floor arcade), the south side was reinstated to its substantial integrity giving the visitors a sense of completeness and magnificence of the monument (main hall diameter is $25 \mathrm{~m}$ ), though some parts are still missing, especially in the dome, leaving the overall height reduced to only $24 \mathrm{~m}$ instead of the originally $32 \mathrm{~m}$.

\subsection{Impact of tramways and railways}

The location of the monument is very critical in terms of interaction with the surrounding urban traffic. Since the early 20th century, the adjacent Via Giolitti was provided with urban tramways, which are still regularly working, so that heavy modern trams pass by very close to the west side of the monument. On the opposite side of the monument, a few meters from the building to the north-east, several railway tracks serve the main railway station in Rome, the Termini station, which are there since pope Pious IX started the first railway line in Rome (Rome-Frascati), in 1856 [11], as testifies the photo in Fig. 1(b).

\subsection{Vibration measurements}

Traffic vibrations were monitored at the monument foundations in four different sessions: on July $4^{\text {th }}, 2016$ [12], February $1^{\text {st }}, 2017$, April $19^{\text {th }}, 2017$ and July $13^{\text {th }}, 2017$. The measurements were carried out from $9.00 \mathrm{a} . \mathrm{m}$. to $2.00 \mathrm{p} . \mathrm{m}$. in order to assess the vibrations induced by nearby rush-hour traffic (road, trains and trams), (Fig. 2(a)). Several positions were acquired at the bases of the 10 pillars both at inner and outer sides, as well as at the bases of other walls, in order to map the base excitation to the structure (Fig. 2(b)).
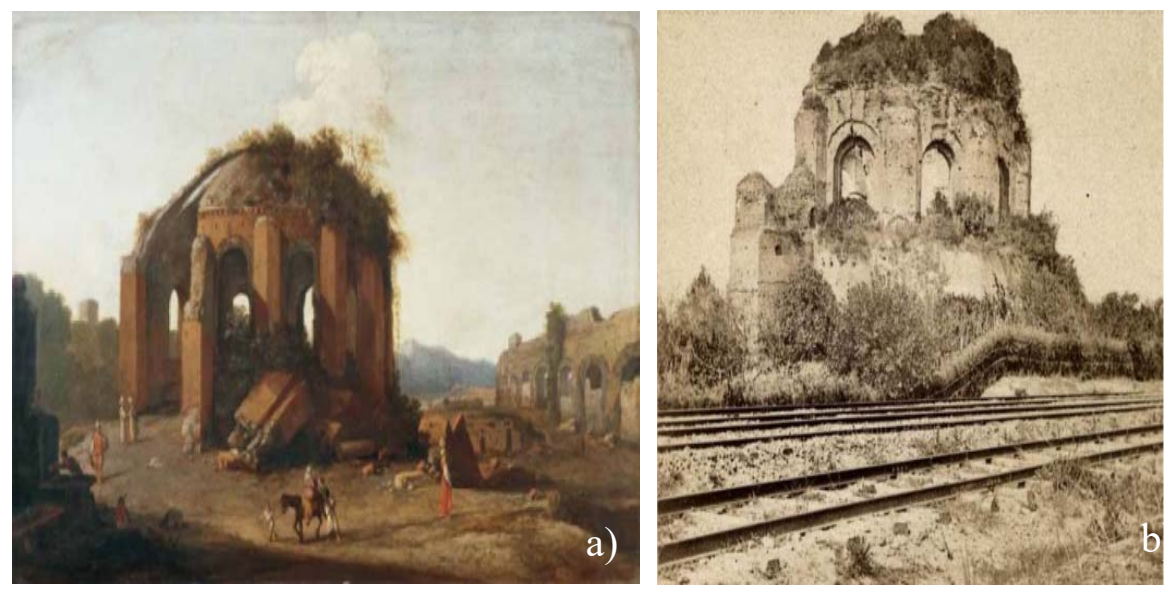

Figure 1: (a) View from East of the temple of Minerva Medica, painting by Bartholomeus Breenbergh, 1627. (b) Railway tracks of the Rome-Frascati line in 1856. 

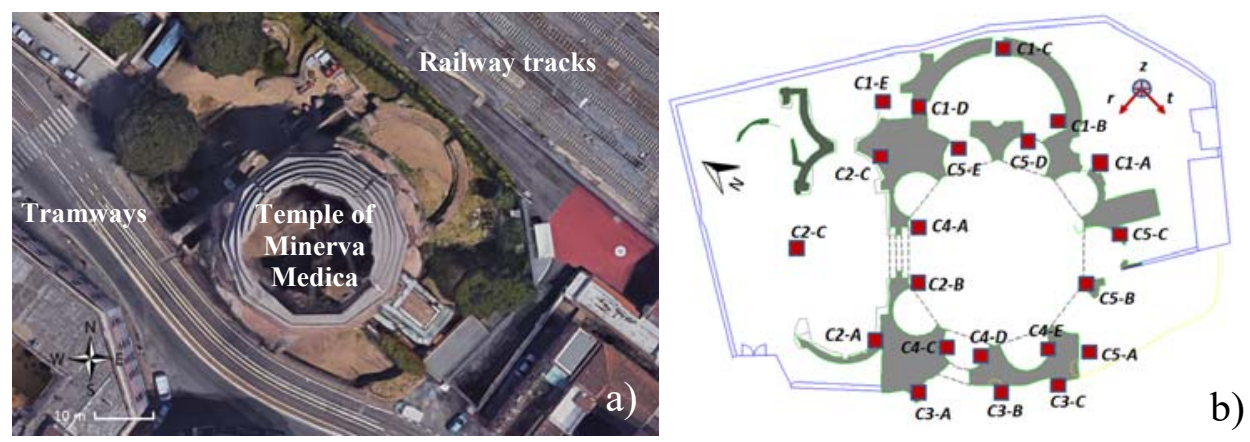

Figure 2: Road with tramways and railway tracks near the temple of Minerva Medica (a). Positions acquired at the base of the monument (b). Recorded components are $r$ for radial (toward the centre of the hall), $t$ for tangential and $z$ for vertical.

The instruments for vibration acquisitions were oriented so as to measure the radial (toward the centre of the decagonal hall), the tangential and the vertical components ( $r, t$ and $z$ respectively in the following). Each position was acquired for at least 20 minutes at a sampling frequency of $200 \mathrm{~Hz}$. During vibration acquisition the time and type of vehicles passages were also noted.

\section{CASE 2: THE CATACOMB OF PRISCILLA}

As a second case, we illustrate the traffic vibration monitoring we carried out at the Catacomb of Priscilla. It is situated just a few kilometres outside of the historic centre of Rome, at a place on the Via Salaria, where an ancient quarry was used for Christian burials (from the late 2 nd century to the 4 th century A.D.).

This catacomb is very important both from an archaeological point of view and from an artistic one, as some of its walls and ceilings display fine decorations illustrating Biblical scenes [13]. In fact, the main artworks in the catacomb are concentrated in the area of the cryptoporticus, which is where the investigations here described are focused on. In particular, the so-called "Greek Chapel" is the most renowned and notable chamber of the catacomb, presenting remarkable architecture decorated with 3rd-century frescoes.

\subsection{Current state of damage of the "Greek Chapel" and structural problems}

In the cryptoporticus area a variety of Non-Destructive Tests (NDTs) and investigations were carried out within the CO.B.RA. project in order to assess the current state of damage of its structures and artworks. Subsequently, the most damaged or potentially vulnerable points of the catacomb were identified and the ambient vibration monitoring was concentrated on verifying their exposure to traffic or other sources vibration.

With particular reference to the "Greek Chapel" locally some preservation problems were identified, such as superficial biotic aggression, extreme moisture conditions and local detachments from the bearing walls (Fig. 3).

Moreover, not far from the cryptoporticus some walls present signs of structural degradation, such as cracks, which in some cases appear quite evident. 

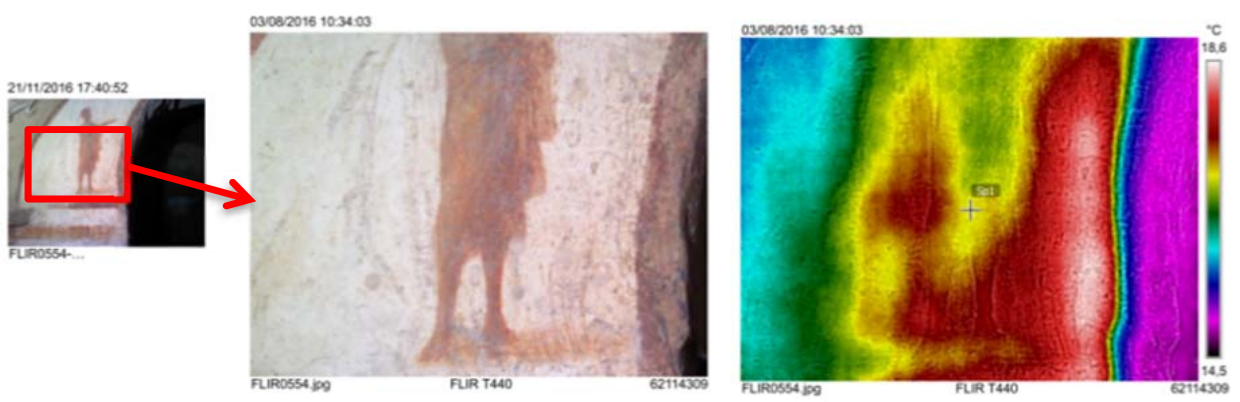

Figure 3: Detachments of the plaster from the bearing walls (red areas in the right box) of frescoes in the Greek Chapel.

\subsection{Impact of road vehicles in via Salaria}

The potential impact of urban transport vibration on the studied section of the Catacomb of Priscilla was essentially due to the road traffic in modern Via Salaria.

As shown in Fig. 4 the studied section of the catacomb is close to the most congested stretch of this road, partly due to the presence of a crossroad at Piazza Priscilla (Priscilla Square). No other urban transport types (trams, train, underground, etc.) are present close to the studied area.

\subsection{Vibration measurements}

Ambient vibration was monitored on $29^{\text {th }}$ July from 8.00 a.m. to 13.00 a.m. The positions of sensors are depicted in Fig. 5 on the map of the tunnels and chambers of the Catacomb of Priscilla level located approximately at the same elevation of the entrance at Via Salaria 277 (47-48 m a.s.1.). The sensors were positioned at the doorstep of the entrance at Via Salaria 277 (position 0), in the cryptoporticus (position 1), near the "Greek Chapel" (position 2), and near the wall displaying the most evident cracks (positions 3 and 4). The sensor located near the entrance was used as reference to assess the traffic vibration near the source (the road vehicles passing by) and as a base for calculating their transmission/amplification to inner monitored measurement positions.

\section{ANALYSIS OF VIBRATION DATA}

From the vibration data acquired in all four monitoring sessions carried out at the temple of Minerva Medica the PCPV values for each monitored position at the base of the monument were obtained. In Fig. 6 the PCPV values are mapped with different colours in four classes as follows:

1. PCPV values $<1.5 \mathrm{~mm} / \mathrm{s}$ (this value corresponds to the strictest limit prescribed by the Swiss standard for archaeological structures);

2. PCPV values comprised between 1.5 and $2.5 \mathrm{~mm} / \mathrm{s}$ (the latter value is the strictest limit prescribed by the German standard for archaeological structures);

3. PCPV values comprised between 2.5 and $5.0 \mathrm{~mm} / \mathrm{s}$ (the latter value is the limit prescribed by the German standard for residential buildings);

4. PCPV values $>5.0 \mathrm{~mm} / \mathrm{s}$. 


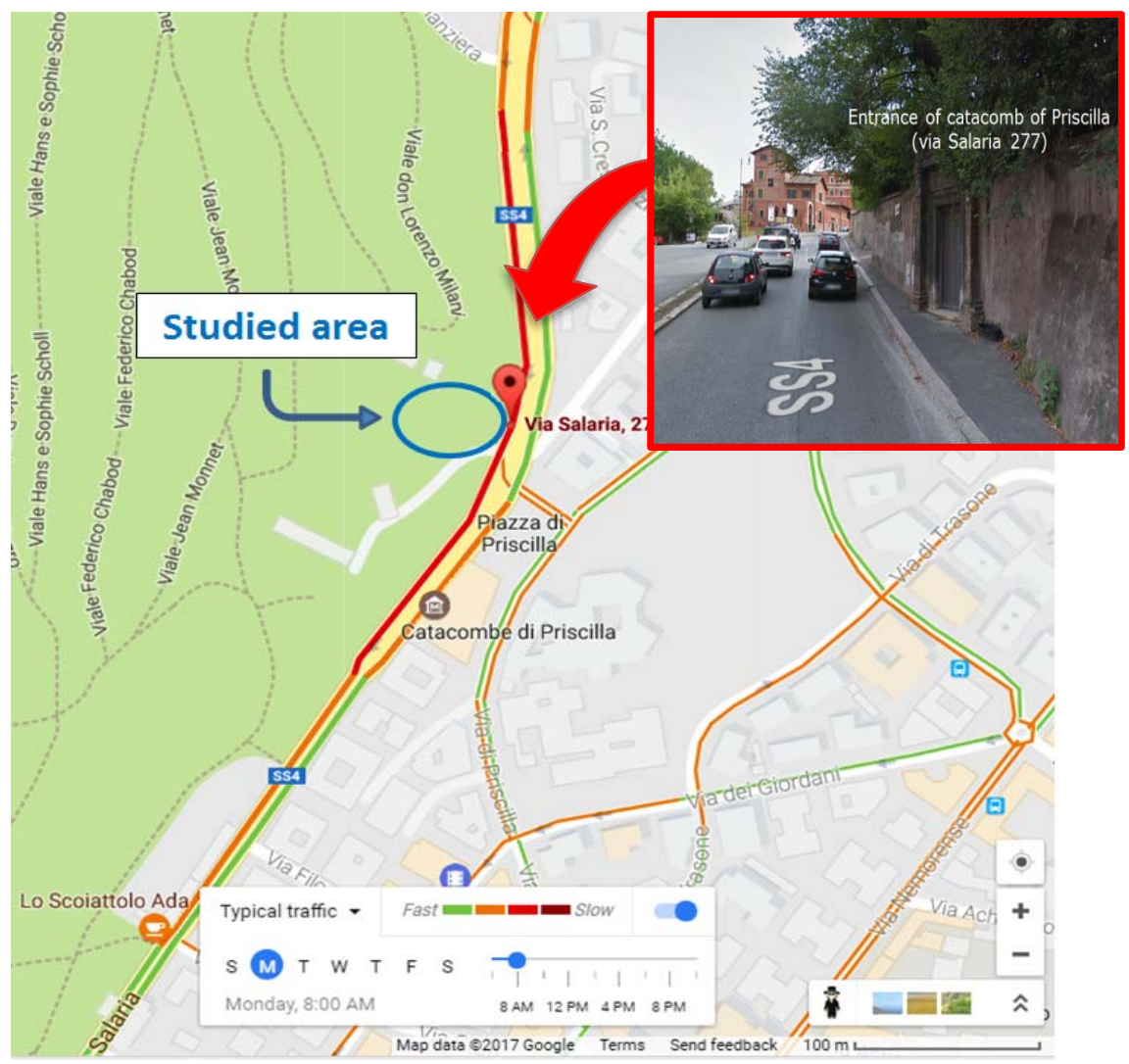

Figure 4: Typical traffic conditions in rush-hour (8.00 a.m. of working day) in via Salaria near the studied section of the Catacomb of Priscilla.

Taking note of the passage time of the several traffic vehicles (road traffic, tramways and trains) the different impact of each type of traffic source could be assessed. In particular, common road traffic originated vibrations with PCPV lower than $0.2 \mathrm{~mm} / \mathrm{s}$ in all acquisitions. Train passages gave higher vibration levels, but PCPV was never greater than $1.5 \mathrm{~mm} / \mathrm{s}$. Train and tram passages produced similar values of peak velocity on the north-east side, near the railway tracks. In all other positions, tram passages induced the strongest vibrations.

In particular, the highest PCPV values were recorded at the positions closest to the tramway, reaching almost $20 \mathrm{~mm} / \mathrm{s}$, which would be over the limit even for industrial constructions according to the German standard $(10 \mathrm{~mm} / \mathrm{s})$. In addition, several points of the pillars in the southwestern side of the monument gave PCPV values comprised between 1.4 and $1.5 \mathrm{~mm} / \mathrm{s}$, so they are lower but very close to the Swiss limit.

On the contrary, in the catacomb of Priscilla PCPV values were always lower than 0.1 $\mathrm{mm} / \mathrm{s}$ in all recorded positions, which is a very low-intensity level. Traffic vibration transmission to each monitored position with respect to the entrance at Via Salaria 277 was also evaluated in terms of ratio between the root-mean-square velocity (VRMS). As depicted in Fig. 7, the traffic vibration was almost halved in the cryptoporticus, and furtherly reduced to about one third in all other monitored positions. 


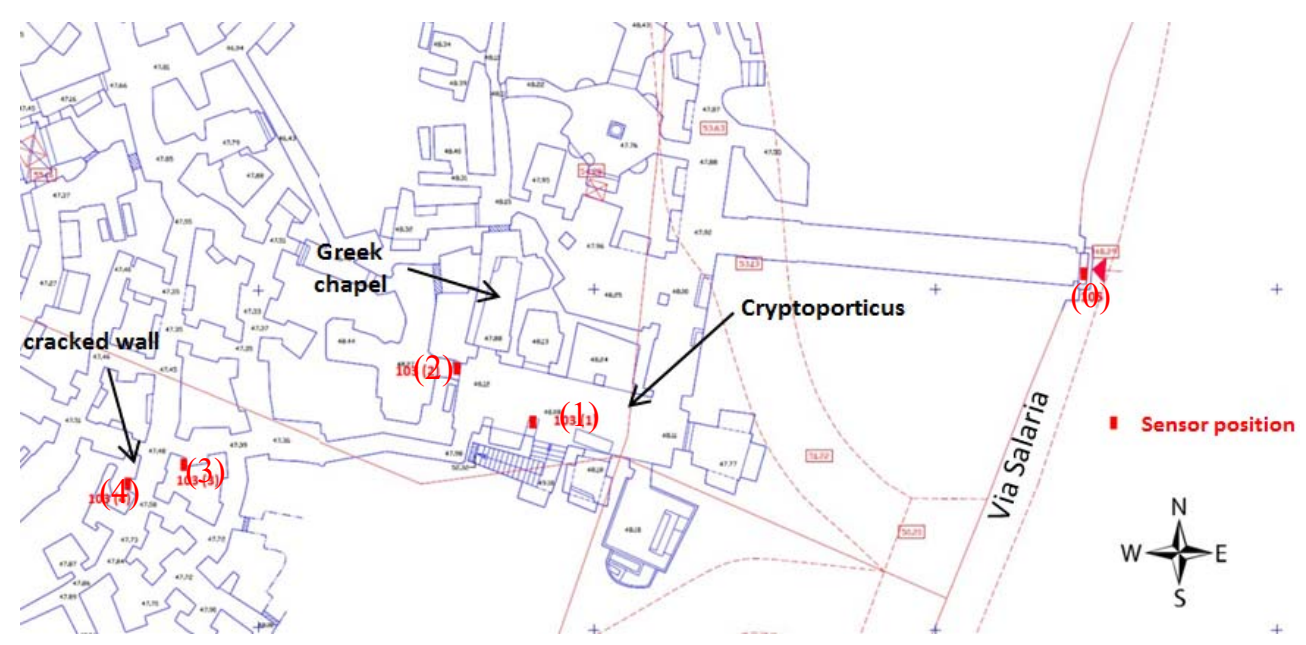

Figure 5: Positions of the sensors (in red with numbers in brackets) for the ambient vibration monitoring with respect to the main features of the cryptoporticus area of the Catacomb of Priscilla.

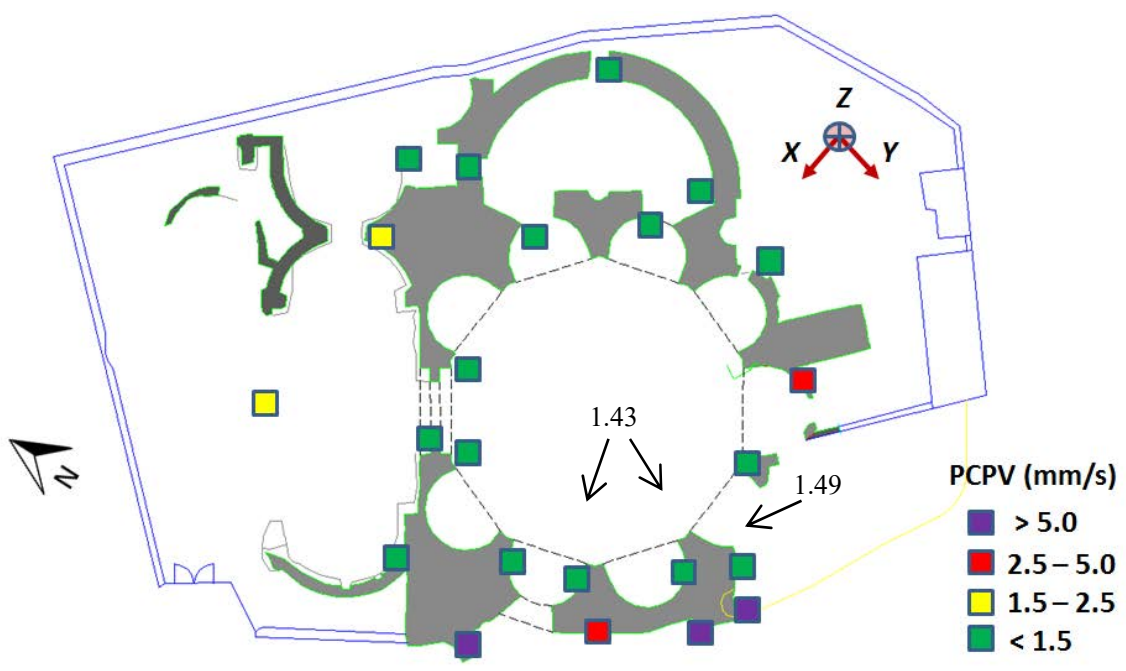

Figure 6: Peak Component Particle Velocity (PCPV) measured at each monitored position at the base of the Temple of Minerva Medica. 


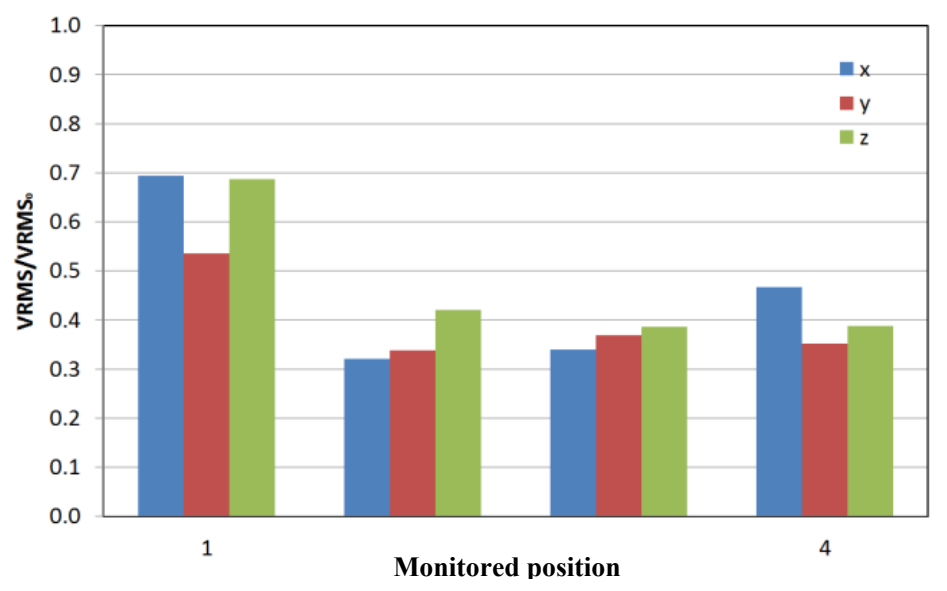

Figure 7: Traffic vibration transmission in terms of ratio between the root-mean-square velocity (VRMS) of each monitored position of the Catacomb of Priscilla and of the entrance at Via Salaria 277. Position numbers are illustrated in Fig. 5.

\section{CONCLUSIONS}

In the present paper, the traffic vibrations induced on two archaeological sites located in Rome were studied. On the one hand, the so-called Temple of Minerva Medica resulted subjected to strong vibrations induced essentially by the trams passing very close to the southwestern side of the monument. On the other hand, the Catacomb of Priscilla is exposed to road traffic vibrations of one of the most congested stretches of Via Salaria. Nonetheless, the recorded vibrations in the most valuable and significant points of the catacomb resulted of practically negligible intensity.

The above results demonstrated that the sustainability assessment of urban transport systems should include the impact of traffic vibration, especially in sites with the presence of constructions with relevant structural vulnerability, such as the archaeological sites. All the more so, since it can potentially lead to surprising conclusions in contrast with the common perception of urban sustainability. In fact, in the two described cases we found that commonly perceived sustainable transport systems, like trams, had much greater impact than road traffic, which is widely considered more unsustainable from other points of view.

\section{REFERENCES}

[1] Sernaa, A., Gerrikagoitiab, J.K., Bernabéa, U. \& Ruizc, T., Sustainability analysis on Urban Mobility based on Social Media content. Proceedings of the 3rd Conference on Sustainable Urban Mobility (3rd CSUM 2016), 2016, Volos, Greece.

[2] Meschik, M., Reshaping City Traffic Towards Sustainability Why Transport Policy should Favor the Bicycle Instead of Car Traffic. Procedia - Social and Behavioral Sciences, 48, pp. 495-504, 2012.

[3] Zito, P. \& Salvo, G., Toward an urban transport sustainability index: an European comparison. Eur. Transp. Res. Rev., 3, pp. 179-195, 2011.

[4] Goldman, T. \& Gorham, R., Sustainable urban transport: Four innovative directions. Technology in Society, 28, pp. 261-273, 2006. 
[5] World commission on environment and development. Our common future. New York: Oxford University Press, 1987.

[6] Athanasopuolos, G.A. \& Pelekis, P.C., Ground vibrations from sheetpile driving in urban environment: measurements, analysis and effects on buildings and occupants. Soil Dynamics and Earthquake Engineering, 19, pp. 371-387, 2000.

[7] CO.B.RA. project website, http://cobra.enea.it/english.

[8] DIN 4150, Erschütterungen im Bauwesen - Einwirkungen auf baulichen Anlagen, (in German), 2015, German standard.

[9] SN 640312 a, Effet des ébranlements sur les constructions, (in French), 1992, Swiss standard.

[10] Barbera, M., Magnani Cianetti, M. \& Barrano, S., Da Massenzio a Costantino: le indagini in corso nel c. d. tempio di Minerva Medica, Proceedings of the International Conference of CISEM - La villa restaurata e i nuovi studi sull'edilizia residenziale tardoantica (in Italian), 2014.

[11] Panconesi, M., Le ferrovie di Pio IX (in Italian), ed. Calosci, Cortona 2005.

[12] Roselli, I., Fioriti, V., Bellagamba, I., Mongelli, M., Tatì, A., Barbera, M., Magnani Cianetti, M. \& De Canio, G., Impact of traffic vibration on the temple of Minerva Medica, Rome: preliminary study within the CO.B.RA. project. International Journal of Heritage Architecture, (in press).

[13] Bisconti, F., Mazzei, B. \& Giuliani, R., La catacomba di Priscilla. Il complesso, i restauri, il museo. (in Italian), Tau, Todi 2013. 